\title{
A SERIOUS GAME AGAINST DOPING: EVALUATION OF GAME USABILITY, EASE AND USERS' ENJOYMENT
}

\section{Efthymios ZIAGKAS ${ }^{*}$, Agisilaos CHALDOGERIDIS ${ }^{2}$, Nikolaos POLITOPOULOS ${ }^{2}$, Thrasyvoulos TSIATSOS ${ }^{2}$, Vassilis BARKOUKIS ${ }^{1}$}

\footnotetext{
${ }^{1}$ Aristotle University of Thessaloniki, Faculty of Physical Education and Sport Science, Thessaloniki, Greece

${ }^{2}$ Aristotle University of Thessaloniki, Faculty of Informatics, Thessaloniki, Greece
}

https://doi.org/10.35189/dpeskj.2020.59.s.2

\begin{abstract}
Doping is a threat to sport worldwide. Doping not only exists in professional sport, but also affects recreational athletes who increasingly use performance-enhancing drugs. As anti-doping authorities largely rely on detection, deterrence, and prevention to tackle doping use, the main tool for prevention is education. So far, educational interventions have largely used traditional teaching approaches such as face-to-face courses and online courses. The present study examines the usability of a serious game against doping (the GAME) as an alternative approach to traditional anti-doping education. In addition, this study will investigate its ease and users' enjoyment while playing the serious game. Participants in the evaluation were 21 undergraduate students who played the GAME and then were asked to respond to a questionnaire evaluating GAME's usability, ease and users' enjoyment. Concerning the usability and ease of GAME, the results demonstrated the high usability and ease of GAME. The findings related to the evaluation of users' enjoyment were also positive. Overall, players were largely satisfied with their gaming experience, rating the GAME as easy to understand and learn and very satisfying. The next step is to deploy the GAME in greater audiences and evaluate its effectiveness in changing beliefs and knowledge about doping.
\end{abstract}

Keywords: serious games, game-based learning, anti-doping, sports, evaluation.

\section{Introduction}

\section{Doping in sports}

In order to increase their physical performance and obtain higher achievements in sports, athletes often use alternative methods to increase their training workload (Mazzeo, 2016). For years, athletes have tried to improve artificially their physical performance. Elite athletes are using several legal or illegal, healthy, or unhealthy methods in their effort to improve their performance (Mazzeo et al., 2016; Santamaria et al., 2013; Sjöqvist et al., 2008; AgullóCalatayud et al., 2007). The reasons of these efforts vary and are changing over time (Lazuras et al., 2015; Nicholls et al., 2017). Furthermore, several actors are also involved in the process, such as friends and relatives of the athletes, and the athletes' entourage including medical staff, managers, chemists, biologists and pharmacists, as well as pharmaceutical industries, clandestine laboratories and criminal organizations (Marclay et al., 2013; Esseiva et al., 2007). Doping is nowadays considered as a public health issue that concerns the whole society (Lippi et al., 2008; Council of Europe, 1989) and also a threat to sport. Doping undermines the fundamental principles of sport about open and fair competition (Mottram, 2005). It is a behaviour that discourages the practice of sport in general and creates pressure on athletes who compete clean. It seriously affects the image of the sports industry and is a serious threat to the athletes' health (Council of Europe, 1989; Mazzeo et al., 2016). 
Although doping has been associated with competitive sport, it also affects recreational athletes who increasingly use performance-enhancing drugs (Lazuras et al., 2017; Mazzeo, 2016). In particular, a study shows that doping use can be initiated among amateur athletes as young as 10 years old (Nicholls et al., 2017). Accordingly, another study shows that, on average, 1 out of 5 young amateur athletes and exercisers aged between 16-25 years have used doping substances at least once in their lifetime, with higher prevalence rates being reported in South-East European countries like Greece (27.6\%) and Cyprus (28.9\%), and lower prevalence rates in Germany (17\%) and the UK (14.6\%) (Lazuras et al., 2017). The increased prevalence of doping use in both competitive and recreational sports calls for an effective treatment, and scholars have recently advocated for an education-based approach against doping (Barkoukis, 2015).

\section{Anti-doping education}

The fight against doping largely focuses on three main pillars: detection, deterrence, and prevention. Testing for banned substances, gathering evidence, and imposing penalties for doping violations serve both detection and deterrence goals. With good testing systems, no athlete using prohibited means or methods should feel secure. The main tool of prevention is education (Cleret, 2011). However, this approach was found ineffective as doping prevalence remains as high as it was. To address this gap, education has been suggested as an alternative and potentially more influential approach to tackle doping use (Barkoukis, 2015). In response to this call, a number of educational interventions have been developed.

Such an example is the SafeYou Program (SafeYou, 2015) focused on recreational athletes. It consists of eight sessions that can be self-administered or educator-facilitated. Moreover, the educational material includes case studies from recreational athletes that are aimed to be used during the teaching process. Several of these case studies are illustrated via video in order to facilitate the educational process. In addition, the educational material includes a guide for facilitators indicating how to use problem-based learning. Furthermore, the educational material includes an interactive video providing a more gamified approach to teaching. Also, five videos with testimonials and information about doping are provided to help learners (and facilitators) deepen their understanding of the educational material. This material was further expanded with 12 Sessions grouped into eight stand-alone Themes to address the needs of competitive athletes. In addition, a mobile PAES information application was developed to assist learning, especially on the health side effects of doping use.

Another attempt involves the Coaches and Sport Integrity course, which is focused on the education of pre- and in-service coaches to sports integrity. The course includes 13 sessions for pre-service coaches and six for in-service coaches, and addresses corruption in sports, doping, match fixing, good governance, and whistleblowing. Another interesting educational approach is DELTS (Doping E-Learning Tools) that involves a series of six sessions on the side effects of doping. The course targets recreational sport athletes and is self-administered through an online platform. Another educational intervention developed for competitive athletes is My-choice that aims to influence specific psychological variables related to the decision to dope. More specifically, the program aims, through six sessions, to educate athletes on moral disengagement and self-regulatory efficacy. 
All above-mentioned educational interventions targeted athletes. However, in line with Barkoukis et al. (2019) who have suggested that coaches are an influential agent in the decision-making process towards doping, the CoachMADE intervention (Ntoumanis et al., 2018) was developed to assist coaches to establish optimal motivational climates and prevent their adolescent athletes from current and future willingness to dope. The intervention consists of two seminars focused on developing a need-supportive motivational climate that facilitates coach-athlete interactions in general and on doping-related issues (e.g., checking for prohibited substances in athletes' medication).

However, recent evidence has demonstrated that athletes are not interested in attending anti-doping education (Loukovitis et al., 2020). Therefore, there is a need to advance antidoping educational efforts for both competitive and recreational athletes. More specifically, there is a need to move forward and transform the way anti-doping education is designed, delivered, and evaluated. Towards this end, serious game learning can assist in reaching wider range of recipients, young and adolescent athletes, competitive and recreational athletes, elite and amateur athletes, and providing education on doping to the populations that may not be at risk for doping use. Therefore, there is a need to transform and advance antidoping education by improving its design, delivery, and evaluation. In this respect, innovative and meaningful anti-doping educational interventions are required. Towards this end, serious game learning can assist in reaching wider range of recipients, young and adolescent athletes, competitive and recreational athletes, elite and amateur athletes, and providing education on doping to the populations that may not be at risk for doping use.

\section{Serious games}

Serious gaming is a priority area for information and technology researchers having recognised the potential of games, for example, teaching and training, social inclusion, health, digital transformation, and other societal purposes. The main advantages provided by serious games include appeal, since nowadays technologies are commonly used in daily life, being able to enhance more people's engagement (Andrade et al., 2014) because games are fun and can increase motivation and effectiveness, decreasing patients' dropout since they can experience new behaviours in a safe environment (Fleming et al., 2014).

The movement towards the use of serious games as training and learning is proliferated by the perceived ability of such games to create a memorable and engaging learning experience. Various commentators and players alike argue that serious games can develop and reinforce 21 st century skills such as collaboration, problem solving and communication. While, in the past, players and trainers were reluctant to use serious games for improving skills and competencies, there is currently an increasing interest in exploring how serious games could be used to improve specific skills and competencies. The overarching assumption made is that serious games are built on sound learning principles encompassing teaching and training approaches that support the design of authentic and situated learning activities in an engaging and immersive way. Developing serious games based on activity-centred pedagogies that enable trainees to actively engage with questions and problems associated with sport activity and dual careers is an empowering approach with benefits for both subject learning and developing a wide range of important high-order intellectual attributes including the notion of 
'transferability', that is being able to situate specific skills in different settings and contexts, a competence much needed (Barkoukis et al., 2020).

\section{A serious game against doping}

Currently, there is a need to advance anti-doping educational efforts and develop educational tools for both competitive and recreational athletes. Nowadays, several antidoping educational interventions aiming to tackle doping use in competitive and recreational sports have been developed. However, there is a need to transform and advance the design, delivery mode and evaluation of anti-doping education. Serious gaming can contribute to anti-doping education by providing a serious game that will reach wider audiences of athletes as compared to the existing anti-doping education interventions. Furthermore, such a serious game will include an innovative educational approach that is more suitable for teaching adolescents and young athletes. Thus, the aim of this study is firstly to present the development and objectives of a serious game (i.e., the GAME) against doping, and secondly, to evaluate GAME's usability, ease and users' enjoyment.

\section{Methodology}

\section{Participants}

This study included 21 participants. All participants were Information and Technology students at the Aristotle University of Thessaloniki. Their mean age was 23.4 years (SD $= \pm$ 4.1 years). Thirteen participants were males and eight were females. In order to be included in this research, all participants read the information sheet with information about the study, declared that they understood their tasks during the study, they understood that their participation was voluntary, that they could leave the research at any time they wanted without giving explanations and provided consent to take part in the study.

\section{Development of the GAME}

In order to deliver an innovative and impactful anti-doping educational intervention, the proposed serious game utilises: (a) existing research on doping use from the social and behavioural sciences; (b) innovative learning pedagogies; and (c) modern serious gaming design and technology. A state-of-the-art about e-learning platforms and the existing game engines research was conducted, and the result was the selection of the most suitable platform that fitted the project's needs. The game engine that most suited the needs of the project was Unity ("Unity for all", 2020). A concept design of these games was created to demonstrate the main structural idea behind them (Figure 1). Players have to be involved in realistic scenarios that aim to improve their personal skills, such as communication, and allow them to self-regulate. 

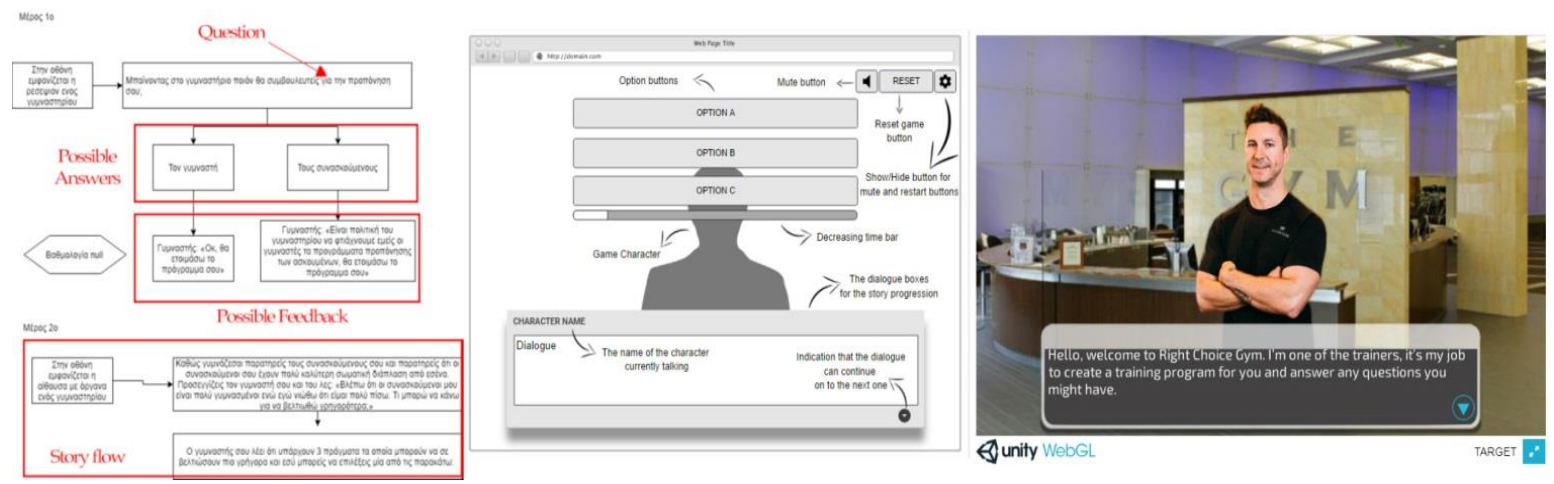

Figure 1. The structure of pedagogical scenarios, GAME design and final version of GAME

The development of the frame required the cooperation between psychologists and antidoping education experts on the one hand, and e-learning experts and game developers, on the other hand. To facilitate cooperation, the development team exploited flowcharts and mock-up tools that created a common basis of what each member of the team should do. For example, psychologists and anti-doping education experts were asked to present pedagogical scenarios using specific flowcharts, whereas e-learning experts and game developers made suggestions on game flow, user feedback, awards, badges, and game scoring system. The team collectively decided on the content and flow of the serious game.

\section{Instruments}

A questionnaire of 68 items was used. Responses were anchored on a seven-point Likert scale. In this Likert scale, 1 was used for totally disagree and 7 for totally agree responses, whereas number 4 was used for neutral responses. Two items included questions concerning knowledge about doping in sports. Twenty-five items included questions concerning usability and ease of the serious game based on the methodology described by Harrison et al. (2013). The last 41 items referred to learners' enjoyment of the GAME play based on a modified version of EGameFlow (Fu et al., 2009). The original version of EGameFlow consists of 52 items measuring eight dimensions: social interaction, goal clarity, immersion, feedback, challenge, concentration, control, and knowledge improvement. In the modified version of EGameFlow, we included the same number of dimensions using the 41 items that accurately described the content of the dimensions that were more relevant to the GAME.

\section{Procedure}

The evaluation of the GAME took place within the premises of the Faculty of Informatics and Technology at the Aristotle University of Thessaloniki. All participants visited a properly designed room with the required number of computers. After a briefing, which included information about the aims and objectives of the GAME, all participants had the time to play all stages of the game and provide feedback and their scores. Participants played the GAME for four hours. After finishing playing the game, they completed the study questionnaires. 


\section{Data analysis}

All analyses were performed using SPSS version 26.0 (Statistical Package for the Social Sciences for Windows, Chicago, IL). After data collection, descriptive statistics have been used in order to evaluate the variables describing GAME's usability, ease and users' enjoyment. Means, standard deviations, analyses of frequencies and modes were used.

\section{Results}

As regards the two questions concerning the knowledge about doping in sports, users did not give any negative or neutral answers (from 0 - Totally disagree to 4 - Neutral). More specifically, most users say that they slightly agree (5), agree (6) or they totally agree (7) in both questions (Table 1).

Table 1. Knowledge about doping in sports

\begin{tabular}{|c|c|c|c|c|c|c|c|c|}
\hline & $\begin{array}{c}\text { Totally } \\
\text { disagree }\end{array}$ & Disagree & $\begin{array}{l}\text { Slightly } \\
\text { disagree }\end{array}$ & Neutral & $\begin{array}{c}\text { Slightly } \\
\text { agree }\end{array}$ & Agree & $\begin{array}{l}\text { Totally } \\
\text { agree }\end{array}$ & Total \\
\hline $\begin{array}{l}\text { It helps me better } \\
\text { understand the issue of } \\
\text { doping in sports. }\end{array}$ & 0 & 0 & 0 & 0 & 28.6 & 42.9 & 28.6 & 100 \\
\hline $\begin{array}{l}\text { It helps me better } \\
\text { understand the health risks } \\
\text { associated with doping. }\end{array}$ & 0 & 0 & 0 & 0 & 28.6 & 28.6 & 42.9 & 100 \\
\hline
\end{tabular}

Concerning the usability and ease of GAME, almost all answers ranged between 5 (slightly agree) and 7 (totally agree), showing its high usability and ease. The only answer showing to be neutral (4) was to question 18, "I quickly became a skilled user". As presented in Table 2, multiple modes exist in this question, and the smallest value is shown.

Table 2. Usability and ease of GAME

\begin{tabular}{llcc}
\hline $\begin{array}{l}\text { Question } \\
\text { no. }\end{array}$ & & N & $\begin{array}{c}\text { Answers } \\
\text { mode }\end{array}$ \\
\hline Q1 & It is useful & 21 & 6 \\
Q2 & It gives me better control over my daily work & 21 & 5 \\
Q3 & It makes it much easier to do what I want to do & 21 & 5 \\
Q4 & It works as I would expect a doping training game to work & 21 & 6 \\
Q5 & It is easy to use & 21 & $5^{*}$ \\
Q6 & It is simple to use & 21 & 7 \\
Q7 & It is user friendly & 21 & 5 \\
Q8 & Requires the least possible steps to complete the tasks I want to do with it & 21 & 6 \\
Q9 & It is flexible & 21 & 5 \\
Q10 & Its use does not require much effort & 21 & $5^{*}$ \\
Q11 & I can use it without reading written instructions & 21 & 6 \\
Q12 & I did not notice any inconsistencies in its use & 21 & $5^{*}$ \\
Q13 & I think both casual and regular users will like it & 21 & 6 \\
Q14 & I can handle mishandling easily and quickly & 21 & $5^{*}$ \\
Q15 & I can use it at any time & 21 & 5
\end{tabular}


Q17 I can easily remember its operation $\quad 21 \quad 5$

Q18 I quickly became a skilled user $\quad 21 \quad 4 *$

Q19 I am satisfied with its use $\quad 21 \quad 5$

Q20 I would recommend it to a friend of mine $\quad 21 \quad 6 *$

Q21 Its use is fun $\quad 21 \quad 6$

Q22 It works exactly as I want it to work $\quad 21 \quad 6$

Q23 It is wonderful $\quad 21 \quad 5$

Q24 I feel I need it $\quad 21 \quad 6$

Q25 Its use is pleasant $\quad 21 \quad 27$

*Multiple modes exist. The smallest value is shown.

Finally, regarding learners' enjoyment, based on answers modes, users did not give any negative answer (from 0 - Totally disagree to 3 - Neutral). In almost all questions, answers mode ranged between 5 (slightly agree) and 7 (totally agree), showing the high enjoyment of the GAME play. In 5 out of the 41 questions, the answer mode was neutral, more specifically, in questions Q9, Q11, Q26, Q28 and Q29. In questions Q9, Q11and Q28, as described in Table 3, multiple modes exist and the smallest value is shown.

Table 3. Results concerning learners' enjoyment

\begin{tabular}{|c|c|c|c|c|}
\hline No. & Dimension & & $\mathrm{N}$ & $\begin{array}{l}\text { Answers } \\
\text { mode }\end{array}$ \\
\hline Q1 & Concentration & Most of the gaming activities are related to the learning task & 21 & 5 \\
\hline Q2 & & No distraction from the task is highlighted & 21 & 6 \\
\hline Q3 & & Generally speaking, I can remain concentrated in the game & 21 & 6 \\
\hline Q4 & & I am not distracted from tasks that the player should concentrate on & 21 & 6 \\
\hline Q5 & & I am not burdened with tasks that seem unrelated & 21 & 5 \\
\hline Q6 & & Workload in the game is adequate & 21 & 5 \\
\hline Q7 & Goal Clarity & Overall game goals were presented in the beginning of the game & 21 & 7 \\
\hline Q8 & & Overall game goals were presented clearly & 21 & 6 \\
\hline Q9 & & Intermediate goals were presented in the beginning of each scene & 21 & $4^{*}$ \\
\hline Q10 & & Intermediate goals were presented clearly & 21 & 5 \\
\hline Q11 & Feedback & I receive feedback on my progress in the game & 21 & $4 *$ \\
\hline Q12 & & I receive immediate feedback on my actions & 21 & 6 \\
\hline Q13 & & I am notified of new tasks immediately & 21 & 5 \\
\hline Q14 & & I am notified of new events immediately & 21 & $5^{*}$ \\
\hline Q15 & Challenge & $\begin{array}{l}\text { I receive information on my success (or failure) of intermediate } \\
\text { goals immediately }\end{array}$ & 21 & 6 \\
\hline Q16 & & $\begin{array}{l}\text { The game provides "hints" in text that help me overcome the } \\
\text { challenges }\end{array}$ & 21 & 5 \\
\hline Q17 & & $\begin{array}{l}\text { The game provides "online support" that helps me overcome the } \\
\text { challenges }\end{array}$ & 21 & $5^{*}$ \\
\hline Q18 & & $\begin{array}{l}\text { The game provides video or audio auxiliaries that help me overcome } \\
\text { the challenges }\end{array}$ & 21 & 5 \\
\hline Q19 & & The difficulty of challenges increased as my skills improved & 21 & $5^{*}$ \\
\hline Q20 & & The game provides new challenges with an appropriate pacing & 21 & 6 \\
\hline Q21 & & $\begin{array}{l}\text { The game provides different levels of challenges that tailor to } \\
\text { different players }\end{array}$ & 21 & 5 \\
\hline Q22 & Autonomy & I feel a sense of control over interactions between roles or objects & 21 & 6 \\
\hline Q23 & & I know next step in the game & 21 & 5 \\
\hline Q24 & & I feel a sense of control over the game & 21 & 5 \\
\hline Q25 & Immersion & I forget about time passing while playing the game & 21 & 6 \\
\hline Q26 & & I become unaware of my surroundings while playing the game & 21 & 4 \\
\hline Q27 & & $\begin{array}{l}\text { I temporarily forget worries about everyday life while playing the } \\
\text { game }\end{array}$ & 21 & 6 \\
\hline
\end{tabular}




\begin{tabular}{|c|c|c|c|c|}
\hline Q28 & & I experience an altered sense of time & 21 & $4 *$ \\
\hline Q29 & & I can become involved in the game & 21 & 4 \\
\hline Q30 & & I feel emotionally involved in the game & 21 & 5 \\
\hline Q31 & & I feel viscerally involved in the game & 21 & 5 \\
\hline Q32 & $\begin{array}{l}\text { Social } \\
\text { Interaction }\end{array}$ & I feel cooperative toward other classmates & 21 & 5 \\
\hline Q33 & & The cooperation in the game is helpful to the learning & 21 & 6 \\
\hline Q34 & & The game supports social interaction between players (chat, etc) & 21 & 6 \\
\hline Q35 & & The game supports communities within the game & 21 & 6 \\
\hline Q36 & & The game supports communities outside the game & 21 & $5 *$ \\
\hline Q37 & $\begin{array}{l}\text { Knowledge } \\
\text { Improvement }\end{array}$ & The game increases my knowledge & 21 & $5 *$ \\
\hline Q38 & & I catch the basic ideas of the knowledge taught & 21 & $5^{*}$ \\
\hline Q39 & & I try to apply the knowledge in the game & 21 & 5 \\
\hline Q40 & & The game motivates the player to integrate the knowledge taught & 21 & 5 \\
\hline Q41 & & I want to know more about the knowledge taught & 21 & $5 *$ \\
\hline
\end{tabular}

\section{Discussion}

The aim of this study was firstly to present the development of a serious game (the GAME) against doping, and secondly, to evaluate its usability, ease and users' enjoyment. As regards the questions concerning the knowledge about doping in sports, all users stated that GAME made them better comprehend this issue. Also, they mentioned that GAME made them better realize the health risks associated with doping. These findings indicated that the pedagogical scenarios, as designed by sport psychologists and anti-doping education experts, included all up-to-date information about the problem of doping in sports and the health risks associated with doping.

Concerning the usability and ease of GAME, the present results showed that GAME was simple to use, its use was pleasant, and players learned to use it quickly. Furthermore, players agreed that GAME was useful, it worked as they would expect a doping training game to work, and they could use it without reading written instructions. Additionally, players agreed that GAME required the least possible steps to complete the tasks they wanted to do with it, it worked exactly as they wanted it to work, reported that both casual and regular users would like it and feel the need to play the game, its use was fun and they would recommend it to a friend. Lastly, players slightly agreed that GAME gave them better control over their daily work making it much easier to do what they wanted to do, it was easy to use, user friendly, flexible, and its use did not require much effort. Players' answers showed that GAME was slightly wonderful, they did not notice any inconsistencies in its use, could handle mishandling easily and quickly, could use it at any time and were satisfied with its use.

The findings of the 41 questions concerning learners' enjoyment grouped in height dimensions (Knowledge Improvement, Social Interaction, Immersion, Autonomy, Challenge, Feedback, Goal Clarity and Concentration) were quite satisfactory. GAME was globally evaluated based on the aforementioned dimensions by averaging the responses of students to individual questions corresponding to each dimension. As indicated by the results of the analysis, the players' opinion was positive. The only dimensions that had neutral to positive results were the questions "I experience an altered sense of time", "I become unaware of my surroundings while playing the game" and "I can become involved in the game" referring to 
immersion, "Intermediate goals were presented in the beginning of each scene" referring to goal clarity and "I receive feedback on my progress in the game" referring to feedback. The most positive results were found for the Goal Clarity dimension, more specifically in the question "Overall game goals were presented in the beginning of the game", with all participants answering that they totally agreed. It seems that players have adapted really quickly to the game environment and most of the gaming activities are related to the learning task.

\section{Conclusion}

Helping athletes acquire knowledge about doping and especially its severe health side effects is a first step to prevent doping. GAME is the first serious game aiming to improve the knowledge on doping in sports and the health-related issues of doping use. GAME players marked it as an informative, useful, user friendly, and enjoyable game to play. The next step is to deploy the game in greater audiences and evaluate its effectiveness in changing beliefs and knowledge about doping.

\section{Acknowledgement}

This study was conducted with support from the European Commission. This publication reflects the views only of the authors, and the Commission cannot be held responsible for any use which may be made of the information contained therein. The authors of this research would like to thank GAME team who generously shared their time, experience, and materials for the purposes of this project.

\section{References}

Agulló-Calatayud, V., González-Alcaide, G., Valderrama-Zurián, J. C., \& AleixandreBenavent, R. (2007). Consumption of anabolic steroids in sport, physical activity and as a drug of abuse: An analysis of the scientific literature and areas of research. British Journal of Sports Medicine, 42(2), 103-109. http://dx.doi.org/10.1136/bjsm.2007.036228

Andrade, L. H., Alonso, J., Mneimneh, Z., Wells, J. E., Al-Hamzawi, A., Borges, G., Bromet, E., Bruffaerts, R., Girolamo, G. de, Graaf, R. de, Florescu, S., Gureje, O., Hinkov, H. R., Hu, C., Huang, Y., Hwang, I., Jin, R., Karam, E. G., Kovess-Masfety, V. et al. (2014). Barriers to mental health treatment: Results from the WHO World Mental Health surveys. Psychological Medicine, 44(6), 1303-1317. https://dx.doi.org/10.1017\%2FS0033291713001943

Barkoukis, V. (2015). Moving away from penalization: The role of education-based campaigns. In V. Barkoukis et al. (Eds.), The psychology of doping in sport (pp. 215-229). Abingdon: Routledge.

Barkoukis, V., Brooke, L., Ntoumanis, N., Smith, B., \& Gucciardi, D. F. (2019). The role of the athletes' entourage on attitudes to doping. Journal of Sports Sciences, 37(21), 24832491. https://doi.org/10.1080/02640414.2019.1643648 
Barkoukis, V., Tsiatsos, T., Politopoulos, N., Stylianidis, P., Ziagkas, E., Loukovitis, A., Lambros, L., \& Ypsilanti, A. (2020). A serious game approach in mitigating performance enhancement culture in youth (GAME Project). In: M. Auer \& T. Tsiatsos (Eds.), ICL 2018, "The Challenges of the Digital Transformation in Education", Advances in Intelligent Systems and Computing, 916 (pp. 733-742). Cham: Springer. https://doi.org/10.1007/978-3-030-11932-4_68

Cleret, L. (2011). The role of anti-doping education in delivering WADA's mission. International Journal of Sport Policy and Politics, 3(2), 271-277. https://doi.org/10.1080/19406940.2011.577084

Council of Europe. (1989). Anti-Doping Convention. https://www.coe.int/en/web/conventions/full-list/-/conventions/treaty/135

Esseiva, P., Ioset, S., Anglada, F., Gasté, L., Ribaux, O., Margot, P., Gallusser, A., Biedermann, A., Specht, Y., \& Ottinger, E. (2007). Forensic drug intelligence: An important tool in law enforcement. Forensic Science International, 167(2-3), 247-254. https://doi.org/10.1016/j.forsciint.2006.06.032

Fleming, T., Hetrick, S., Cheek, C., Bridgman, H., Thabrew, H., Merry, S., Perry, Y., Stasiak, K., \& Shepherd, M. (2014). Serious games for the treatment or prevention of depression: A systematic review. Revista de Psicopatología y Psicología Clínica, 19(3), 227-242. http://dx.doi.org/10.5944/rppc.vol.19.num.3.2014.13904

Fu, F.-L., Su, R.-C., \& Yu, S.-C. (2009). EGameFlow: A scale to measure learners' enjoyment of e-learning games. Computers \& Education, 52(1), 101-112. https://doi.org/10.1016/j.compedu.2008.07.004

Harrison, R., Flood, D., \& Duce, D. (2013). Usability of mobile applications: Literature review and rationale for a new usability model. Journal of Interaction Science, 1(1). https://doi.org/10.1186/2194-0827-1-1

Lazuras, L., Barkoukis, V., \& Tsorbatzoudis, H. (2015). Toward an integrative model of doping use: An empirical study with adolescent athletes. Journal of Sport and Exercise Psychology, 37(1), 37-50. https://doi.org/10.1123/jsep.2013-0232

Lazuras, L., Barkoukis, V., Loukovitis A., Brand, R., Hudson, A., Mallia, L., Michaelides, M., Muzi, M., Petróczi, A., \& Zelli, A. (2017). "I want it all, and I want it now": Lifetime prevalence and reasons for using and abstaining from controlled performance and appearance enhancing substances (PAES) among young exercisers and amateur athletes in five European countries [published correction appears in Frontiers in Psychology 2018, 25(9): 1162]. Frontiers in Psychology, 8: 717. https://doi.org/10.3389/fpsyg.2017.00717

Lippi, G., Banfi, G., Franchini, M., \& Guidi, G. C. (2008). New strategies for doping control. Journal of Sports Sciences, 26(5), 441-445. https://doi.org/10.1080/02640410701624556

Loukovitis, A., Skoufa, L., \& Barkoukis, V. (2020, in press). An examination of football players' beliefs about anti-doping education. Discobolul - Physical Education, Sport and Kinetotherapy Journal.

Marclay, F., Mangin, P., Margot, P., \& Saugy, M. (2013). Perspectives for Forensic Intelligence in anti-doping: Thinking outside of the box. Forensic Science International, 229(1-3), 133-144. https://doi.org/10.1016/j.forsciint.2013.04.009

Mazzeo, F. (2016). Drug abuse in elite athletes: Doping in sports. Sport Science, 9(2), 34-41. https://www.researchgate.net/publication/311670915_Drug_abuse_in_elite_athletes_Dopi ng_in_sports\#fullTextFileContent

Mazzeo, F., Santamaria, S., Monda, V., Tafuri, D., Dalia, C., Varriale, L., De Biasio, S., Esposito, V., Messina. G., \& Monda, M. (2016). Dietary supplements use in competitive and non-competitive boxer: An exploratory study. Biology and Medicine (Aligarh), 8(4): 294. doi: 10.4172/0974-8369.1000294 
Mottram, D. R. (2005). Prevalence of drug misuse in sport. In Drugs in sport (4th ed., pp. 357-380). London: Routledge.

Nicholls, A. R., Cope, E., Bailey R., Koenen, K., Dumon, D., Theodorou, N. C., Chanal, B., Saint Laurent, D., Muller, D., Andres, M. P., Kristensen, A. H., Thompson, M. A., Baumann, W., \& Laurent, J.-F. (2017). Children's first experience of taking anabolicandrogenic steroids can occur before their 10th birthday: A systematic review identifying 9 factors that predicted doping among young people. Frontiers in Psychology, 8: 1015. https://doi.org/10.3389/fpsyg.2017.01015

Ntoumanis, N., Gucciardi, D. F., Backhouse, S. H., Barkoukis, V., Quested, E., Patterson, L., Smith, B. J., Whitaker, L., Pavlidis, G., \& Kaffe, S. (2018). An intervention to optimize coach motivational climates and reduce athlete willingness to dope (CoachMADE): Protocol for a cross-cultural cluster randomized control trial. Frontiers in Psychology, 8: 2301. https://doi.org/10.3389/fpsyg.2017.02301

SafeYou. (2015). https://www.safeyou.eu/

Santamaria, S., Ascione, A., Tafuri, D., \& Mazzeo F. (2013). Gene doping: Biomedical and law aspect of genetic modification of athletes. Medicina Sportiva, 17(4), 193-199. DOI: $10.5604 / 17342260.1081282$

Sjöqvist, F., Garle, M., \& Rane, A. (2008). Use of doping agents, particularly anabolic steroids, in sports and society. Lancet, 371(9627), 1872-1882.

https://doi.org/10.1016/s0140-6736(08)60801-6

Unity for all. (2020). https://unity3d.com/ 